\title{
Potassium Clearance Measurement
}

National Cancer Institute

\section{Source}

National Cancer Institute. Potassium Clearance Measurement. NCI Thesaurus. Code C106560.

The determination of the amount of the potassium clearance in a sample. 